\title{
METODE
}

\section{MODELIRANJE OBPOTRESNIH POBOČNIH PROCESOV V SLOVENIJI}

\author{
AVTOR \\ dr. Blaž Komac \\ Znanstvenoraziskovalni center Slovenske akademije znanosti in umetnosti, Geografski inštitut Antona Melika, \\ Gosposka ulica 13, SI - 1000 Ljubljana, Slovenija \\ blaz.komac@zrc-sazu.si
}

DOI: $10.3986 / G V 87107$

UDK: 504.4:550.348.435(497.4)

COBISS: 1.01

\section{IZVLEČEK}

\section{Modeliranje obpotresnih pobočnih procesov $v$ Sloveniji}

$V$ članku predstavljamo enega od možnih metodoloških pristopov $k$ izdelavi zemljevidov verjetnosti za nastanek obpotresnih zemeljskih plazov in skalnih podorov $v$ Sloveniji v velikem merilu, na ravni regij ali države. Možnost njihovega nastanka smo ocenili z Newmarkovo metodo, ki obsega oceno plazovitosti z uporabo faktorja stabilnosti in kritičnega pospeška. Podornost smo ocenili z empirično enačbo. Rezultate smo primerjali $z$ modeli plazovitosti ter s podatki o legi pobočnih procesov iz Nacionalne podatkovne baze zemeljskih plazov in obpotresnih skalnih podorov leta $1998 v$ Posočju. Opisali smo vpliv reliefa na lego obpotresnih pobočnih procesov z vidika njihove večje gostote v ovršjih gora, omenili pa tudi nekatere posledice, kot so prispevanje sedimentov $v$ vodotoke in možnost njihovega zajezevanja.

\section{KLJUČNE BESEDE}

geografija naravnih nesreč, potresi, zemeljski plazovi, skalni podori, prožnost, modeliranje, Newmarkova metoda

\section{ABSTRACT}

\section{Co-seismic slope processes in Slovenia}

The article presents one of the possible methods for elaboration of probability maps for co-seismic landslides and rockfalls in Slovenia in large scale (regional and national). The probability of their triggering was assessed by the Newmark's method. The method consists of landslide risk evaluation using stability factor and critical acceleration, while rockfall risk was assessed using an empirical equation. The results were compared with landslide risk models and data on the location of slope processes obtained from the Slovenian National Landslide Database, and of co-seismic rockfalls in the Soča Valley (Posočje) in 1988. In addition, the article describes the influence of the relief on the position of co-seismic slope processes from the perspective of their increased density on mountain ridges. We also describe the main consequences of slope processes, such as their contribution to sediment deposition in water courses and the possibility of their impoundment.

\section{KEY WORDS}

geography of natural hazards, earthquakes, landslides, rockfalls, resilience, modelling, Newmark's method

Uredništvo je prispevek prejelo 13. februarja 2015. 


\section{Uvod}

V vzpetih pokrajinah največ škode ob zmernih in močnih potresih pogosto povzročajo hkratni pobočni procesi (Keefer 1984). Po podatkih iz Italije so najpogostejši obpotresni geomorfni pojavi razpoke (30\%), takoj nato pa sledijo zemeljski plazovi (20\%) in skalni podori (14\%; Prestininzi in Romeo 2000), ki so na primer ob potresu v pokrajini Wenchuan na Kitajskem leta 2008 (M 7,9) vzeli 20.000 življenj (Yin, Wang in Sun 2009).

Velikost v potresu prizadetega območja in magnituda obpotresnih procesov sta odvisna od moči potresa. Pri VI. intenzitetni stopnji pada kamenje in nastajajo majhne razpoke, pri VII. stopnji nastajajo skalni odlomi, pri VII. skalni podori in velike razpoke. Večji pobočni procesi se prožijo pri intenziteti nad VIII, pri IX. stopnji pa nastanejo regionalni podori (Keefer 1984; Vidrih, Ribičič in Suhadolc 2001). Ob potresu v Posočju 12. aprila 1998 (M 5,6; VII.-VIII. EMS) se je sprožilo okrog sto skalnih podorov, ob potresu 12. julija 2004 (M4,9; VI.-VII. EMS) pa 50 manjših skalnih podorov (Vidrih in Ribičič 1998; Vidrih, Ribičič in Suhadolc 2001; Komac in Zorn 2002; Zorn 2002a; Natek, Komac in Zorn 2003; Mikoš, Fazarinc in Ribičič 2006). Močni potresi najpogosteje nastajajo ob regionalnih prelomih, zato lahko glede na oddaljenost od prelomov sklepamo tudi o možnosti nastanka obpotresnih pobočnih procesov. Ob potresih v Italiji je $60 \%$ pobočnih procesov nastalo v razdalji do $10 \mathrm{~km}$ od prelomov, nastajali pa so še do razdalje $25 \mathrm{~km}$ (Gasparini s sodelavci 1997; Esposito s sodelavci 2000; Prestininzi in Romero 2000). Pri potresu v Posočju leta 1998 je 60 \% podorov nastalo v razdalji $400 \mathrm{~m}$ od prelomov, najbolj oddaljen pa je bil $2 \mathrm{~km}$ od najbližjega preloma. Med vsemi potresi na ozemlju Slovenije je $50 \%$ potresov z magnitudo nad 5 nastalo v oddaljenosti do $2 \mathrm{~km}$ od prelomov (preglednica 1).

Preglednica 1: Povezanost magnitude potresa in oddaljenosti epicentra od prelomov (lastni izračun po podatkih: Poljak 2007; Katalog... 2010; N=1577).

\begin{tabular}{lccc}
\hline magnituda & $\begin{array}{c}\text { število potresov } \\
\text { v katalogu }\end{array}$ & $\begin{array}{c}50 \% \text { potresov je nastalo } \\
\text { v oddaljenosti do ... km } \\
\text { od prelomov }\end{array}$ & $\begin{array}{c}90 \% \text { potresov je nastalo } \\
\text { v oddaljenosti do ... km } \\
\text { od prelomov }\end{array}$ \\
\hline nad 7 & 3 & 20 & 40 \\
nad 6 & 16 & 8 & 60 \\
nad 5 & 152 & 2 & 30 \\
nad 4 & 591 & 0,8 & 30 \\
nad 3 & 615 & 0,6 & 3 \\
\hline
\end{tabular}

Ob potresu najbolj nihajo zgornji deli pobočij, saj je tam višji potresni pospešek zaradi topografskega učinka. Do tega pride, ko se potresni valovi od pobočij odbijajo v notranjost gorskega masiva, deloma pa razpršijo navzgor (Davis in West 1973; Bouchon 1973; Geli, Bard in Julien 1988; Natek, Komac in Zorn 2003). Ob potresu z magnitudo 6,7 pri Coalingi v Kaliforniji (ZDA) je bil vodoravni pospešek na dnu pobočja 0,3 g, 25 metrov višje pa 0,5g (Murphy s sodelavci 2000; Petley in Murphy 2001), amplituda potresnih valov ob potresu 1987 v Whittier Narrows v Kaliforniji pa je bila desetkrat višja na 60-metrski vzpetini kot na okoliški ravnini (Spudich, Hellweg in Lee 1996).

Razumljivo je torej, da so na slemenih najpogostejši tudi obpotresni pobočni procesi. Ob potresu v Northridgeju v Kaliforniji 17.1.1994 (M6,7) je kar $56 \%$ od 11.000 plitvih plazov nastalo na zgornji četrtini pobočij, na spodnji pa le $11 \%$. Ob potresu v Posočju leta 1998 so se tri četrtine skalnih podorov sprožile v zgornji polovici pobočij, nad relativno višino $700 \mathrm{~m}$, četrtina pa nad $1000 \mathrm{~m}$ nad dolinskim dnom. Za primerjavo: polovica (vseh) pobočnih procesov iz slovenske Nacionalne podatkovne baze zemeljskih plazov se je sprožila v spodnji polovici pobočij, do relativne višine $300 \mathrm{~m}$ nad dolinskim dnom. 
Obpotresni pobočni procesi so pomemben preoblikovalni dejavnik ovršij, saj »odstranjujejo « in oblijo najvišje, konveksne dele pobočij, oziroma zmanjšujejo naklon najstrmejših delov pobočij (Meunier, Hovius in Haines 2008).

Pri opredelitvi obpotresnih podornih območij si lahko pomagamo tudi z lego melišč, saj se podori ob potresih prožijo na območjih, kjer so se prožili že v preteklosti (in so nastala melišča). Tako se je leta 1998 kar polovica podorov sprožila v vodoravni oddaljenosti manj kot $200 \mathrm{~m}$ od melišč, tri četrtine pa v razdalji manj kot $500 \mathrm{~m}$. Tretjina podorov se je sprožila na nestabilnih (Fs' nižji od 0,2) kamninah (osem na robu kvartarnih teras, štirinajst pa na morenskem gradivu), večina pa v trdnih, pogojno stabilnih kamninah $\left(F s^{\prime}=0,8-0,9\right)$, in sicer deset na dolomitu ter osem na apnencu. $60 \%$ podorov se je sprožilo na pobočjih $\mathrm{z}$ visokim kritičnim pospeškom, kjer sta k proženju prispevala razpokanost in preperelost kamnine. Potresa 1998 in 2004 sta v nižje lege prestavila skoraj milijon $\mathrm{m}^{3}$ gradiva, od tega je slaba tretjina ostala na pobočjih, petina gradiva je dosegla vodotoke, polovica pa lahko doseže vodotoke ob prihodnjih ekstremnih padavinah (Mikoš, Fazarinc in Ribičič 2006).

Izjemen dotok sedimentov v reke s pobočnimi procesi pogosto povzroči njihovo zajezitev (Costa in Schuster 1988; Korup 2002; Korup, McSaveney in Davies 2004; Komac, Natek in Zorn 2008; Fan s sodelavci 2012). Zajezitve so pogoste na tektonsko dejavnih območjih z velikimi višinskimi razlikami med dnom dolin in vrhovi. Ob potresu v kitajski pokrajini Wenchuan je na 828 krajih prišlo do delne (40\%) ali popolne $(60 \%)$ zajezitve rek. Pri zajezitvah pride pri $60 \%$ do preboja v enem mesecu po nastanku jezu, h kasnejšim prebojem pa prispevajo intenzivne padavine. Prej ali slej pride do preboja v večini primerov, in sicer pri $86 \%$ (Fan s sodelavci 2012).

Na našem ozemlju je ob najmočnejšem potresu na Slovenskem z magnitudo 6,9 leta 1511 (Košir in Cecić 2011) skalni podor pod Idrijo zajezil Idrijco, nad Bovcem pa »... sta se dva sosednja hriba zrušila eden proti drugemu ... « in zaprla cesto čez Predel (Cecić 2011, 28). V zadnjem času so brez neposredne zveze s potresi nastale zajezitve ob podoru v dolini Tolminke 10. maja 2004 (Komac in Zorn 2009) in ob zemeljskem plazu v dolini Lučnice (Komac, Natek in Zorn 2008). V Posočju je na začetku holocena pod Polovnikom daljši čas obstajalo Srpeniško jezero, ki bi lahko bilo povezano s skalnim podorom (Buser 1986; Zorn 2002a; Bavec s sodelavci 2004, 276). Do zajezitve je prišlo tudi pod Dobračem ob potresu 1348 (Zorn 2002b). V Sloveniji je s tega vidika lahko problematična približno desetina pobočnih procesov - toliko se jih je sprožilo v majhni oddaljenosti od vodotokov. Boljše razumevanje kompleksne narave obpotresnih pobočnih procesov v poseljenih gorskih pokrajinah omogoča prilagajanje in povečuje družbeno prožnost, posebej v luči načrtovanih umetnih zajezitev, posebej ker so za Posočje značilni vsi omenjeni dejavniki, ki omogočajo nastanek zajezitev:

- plazovitost oziroma podornost,

- s prelomi pogojena tektonska dejavnost s pogostimi potresi,

- razpokanost kamnin $\mathrm{v}$ prelomnih conah zaradi premikov ob prelomih,

- velika relativna višinska razlika (pri Kobaridu je $2045 \mathrm{~m}$ ) in

- pogoste intenzivne padavine (Komac 2005).

S pomočjo Newmarkove metode, ki v geografiji ni uveljavljena, je pa za te namene zelo pogosto uporabljana v geotehniki, smo za kamninsko in potresno pestro ozemlje Slovenije izdelali zemljevide verjetnosti nastanka obpotresnih pobočnih procesov. $\mathrm{V}$ prispevku predstavljamo izračun kritičnega pospeška in verjetnosti proženja obpotresnih pobočnih procesov. Najvišji pričakovani potresni pospešek tal je eden od poglavitnih vzročnih dejavnikov potresnih pobočnih procesov. Premiki ob potresu namreč zmanjšajo kohezivnost in strižno trdnost kamnin (Keefer 1984; Harp in Jibson 1996; Keffer, Wasowski in Del Gaudio s sodelavci 2006). Izračun omenjenih prvin vključuje naklon pobočij, kohezivnost in specifično težo kamnin, globino in nagnjenost drsne ploskve ter težnostni pospešek (Carson in Kirkby 1972; Wilson in Keefer 1985; Miles in Ho 1999; Jibson, Harp in Michael 2000; Miles in Keefer 2001a; 2001b; Jibson in Michael 2009; Chen s sodelavci 2014). 


\section{Metoda}

Newmarkova metoda (Newmark 1965) je namenjena oceni verjetnosti zdrsa togega telesa oziroma gmote, ki drsi po nagnjeni površini. Možnost zdrsa smo izračunali iz kritičnega pospeška ( $\left.a_{c}\right)$. To je pospešek pri potresu, pri katerem teoretično lahko pride do premika skalne ali zemeljske gmote. Do premika pride, ko potresna sila oziroma njegov pospešek premaga trenje oziroma strižno trdnost, zaradi česar pride do drsenja. Ocenili smo še dejavnik varnosti, ki opisuje možnost premika zemeljskih gmot glede na njihove geomehanske lastnosti in naklon pobočja (faktor varnosti - Fs'; Bishop 1955) ter pričakovano teoretično velikost in verjetnost premika. Kritični pospešek glede na naklon površja smo izračunali kot:

$$
a_{c}=\left(F_{s}-1\right) g \sin \alpha
$$

kjer sta $a_{c}$ kritični pospešek glede na naklon pobočja pri določeni vrednosti težnostnega pospeška $(g)$ in $\mathrm{a}_{\mathrm{c}-\mathrm{v}}$ kritični pospešek v vodoravni smeri. Dejavnik varnosti $\left(\mathrm{F}_{\mathrm{s}}{ }^{\prime}\right)$ smo izračunali po enačbi:

$$
F_{s}^{\prime}=\frac{c^{\prime}}{\gamma t \sin \alpha}+\frac{\tan \varphi^{\prime}}{\tan \alpha}+\frac{m \gamma_{w} \tan \varphi^{\prime}}{\gamma \tan \alpha}
$$

kjer je $\alpha$ naklon premikanja gmote, ki smo ga izenačili z naklonom površja [radiani], $\varphi^{\prime}$ efektivni strižni naklon (radiani), $c^{\prime}$ efektivna kohezija $(\mathrm{kPa}), \alpha$ naklon pobočja [radiani], $\gamma\left(\gamma_{w}\right)$ specifična teža kamnin oziroma vode $\left(\mathrm{kN} / \mathrm{m}^{3}\right), t$ debelina premikajoče se gmote $(\mathrm{m}), m$ pa njen nasičeni delež [desetine]. Oznaki Fs je dodan opuščaj, ker gre za regionalno oceno (Jibson 2009) in ne za dejavnik varnosti v ožjem pomenu besede.

Izračunani kritični pospešek, pri katerem se lahko sprožijo pobočni procesi, smo primerjali s pričakovanim potresnim pospeškom za Slovenijo (Lapajne, Šket Motnikar in Zupančič 2001) in ugotovili, kje ga presega in lahko pride do potresnih pobočnih procesov. Izračunali smo še Newmarkov premik $(\mathrm{cm})$ in njegovo verjetnost (\%) ter verjetnost proženja skalnih podorov $\mathrm{z}$ uporabo enačbe, ki so jo v 70. letih 20. stoletja naredili na primeru skalnih podorov v Furlaniji. Pri izračunu s programom ArcGIS 10.2.1 smo uporabili 12,5-metrski digitalni model višin (Digitalni ... 2015), poenostavljeni zemljevid geološke sestave (Zemljevid ... 2012) ter podatke o legi plazov (Komac s sodelavci 2008) in obpotresnih podorov iz leta 1998 (Vidrih in Ribičič 1998). Newmarkov premik sicer ne ustreza neposredno dejanskim premikom ob potresih, temveč je mera za pričakovani velikostni red premikov tal ob potresih v prihodnosti (Jibson, Harp in Michael 2000):

$$
\log D_{N}=0,215+\log \left[\left(1-\frac{a_{c}}{a_{\max }}\right)^{2,341}\left(\frac{a_{c}}{a_{\max }}\right)^{-1,438}\right] \pm 0,510
$$

kjer je Dn Newmarkov premik $(\mathrm{cm})$, $a_{c}$ kritični pospešek, pri katerem lahko pride do porušitve, $a_{\max }$ pa najvišji pričakovani potresni pospešek $\left(\mathrm{cm} \mathrm{s}^{-2}\right)$, ki ga primerjamo s kritičnim pospeškom ter tako ugotovimo, ali je kritični pospešek presežen. Ocenimo lahko tudi možnost premika oziroma verjetnost Newmarkovega premika. To smo izračunali z enačbo (Jibson, Harp in Michael 2000):

$$
P(f)=0,335\left[1-\exp \left(-0,048 D_{N}^{1,565}\right)\right]
$$

kjer je $\mathrm{P}(f)$ ocenjena verjetnost premika tal, $\mathrm{D}_{\mathrm{N}}$ pa Newmarkov premik $(\mathrm{cm})$ (slika 6). 
Preglednica 2: Ocena trdnosti kamnin (Hoek in Brown 1980; 1988; Koloski, Schwarz in Tubbs 1989; Sjöberg 1997; Schellart 2000; Guo 2013; Gallen, Clark in Godt 2014; Parameters ... 2015; Shear ... 2015; Soil... 2015).

\begin{tabular}{llcc}
\hline vrsta kamnin & $\begin{array}{c}\text { kohezija } \\
\left(c^{\prime}, M P a\right)\end{array}$ & $\begin{array}{c}\text { strižni naklon } \\
\left(\varphi^{\prime},{ }^{\circ}\right)\end{array}$ & $\begin{array}{c}\text { specifična teža } \\
\left(y, \mathrm{kN} / \mathrm{m}^{3}\right)\end{array}$ \\
\hline kvartarna glina, melj, pesek & 0,021 & 21 & 20 \\
kvartarni silikatni prod & 0,032 & 32 & 15 \\
kvartarni karbonatni prod & 0,032 & 32 & 15 \\
kvartarni konglomerat & 0,037 & 37 & 23 \\
kvartarni grušč & 0,037 & 37 & 23 \\
kvartarni til in tilit & 0,037 & 37 & 23 \\
terciarne gline & 0,025 & 25 & 13 \\
terciarni peski & 0,035 & 35 & 15 \\
terciarni peščenjaki in konglomerati & 0,031 & 31 & 24 \\
terciarni laporji & 0,028 & 28 & 23 \\
neogenski (litotamnijski) apnenci & 0,037 & 37 & 25 \\
mezozojski in terciarni apnenci & 0,037 & 37 & 25 \\
mezozojski masiven apnenec & 0,037 & 37 & 25 \\
mezozojski ploščat apnenec & 0,037 & 37 & 25 \\
mezozojski apnenec in dolomit & 0,037 & 37 & 25 \\
mezozojski dolomit & 0,037 & 37 & 23 \\
mezozojske karbonatne klastične kamnine & 0,032 & 32 & 23 \\
paleozojski glinovci & 0,025 & 25 & 24 \\
paleozojski peščenjak & 0,031 & 31 & 18 \\
vulkanoklastiti (tuf) & 0,030 & 30 & 28 \\
predornine & 0,037 & 37 & 27 \\
globočnine & 0,037 & 37 & 26 \\
slabo odporne metamorfne kamnine & 0,025 & 25 & 26 \\
odporne metamorfne kamnine (gnajs, blestnik) & 0,030 & 30 & 23 \\
predkambrijske visokometamorfne kamine & 0,025 & & \\
\hline & & 25 \\
\hline
\end{tabular}

\section{Rezultati in razprava}

S pomočjo ocenjenih podatkov o trdnosti kamnin (preglednica 1) in reliefnimi kazalniki, izračunanimi na podlagi digitalnega modela višin, smo po Newmarkovi metodi izračunali dejavnik varnosti in od njega odvisni kritični pospešek za ozemlje Slovenije ter verjetnost Newmarkovega premika.

Prostorska razporeditev dejavnika varnosti, ki prikazuje stabilnost pobočij, se ujema s podatki o legi zemeljskih plazov iz Nacionalne podatkovne baze zemeljskih plazov (slika 1): $60 \%$ jih je na nestabilnih območjih, $4 \%$ na pogojno stabilnih, $36 \%$ pa na stabilnih. Visok delež pobočnih procesov na stabilnih območjih (slika 3) kaže na to, da podatkovna baza obsega tudi skalne podore. To je posledica neenotnega zajema, kar smo že ugotavljali v preteklosti (Komac in Zorn 2007; Zorn in Komac 2008).

Zemeljski plazovi so običajno pogostejši pri nizkih vrednostih kritičnega pospeška tal $\left(a_{c}\right)$, ko je za premik gradiva na pobočju nujna nižja sila, skalnih podorov pa je več pri višjem kritičnem pospešku

Slika 1: Zemljevid stabilnosti pobočij v Sloveniji, izračunan $z$ dejavnikom varnosti. $>$ str. 122 Slika 2: Kritični pospešek pobočij v Sloveniji. str. 123 

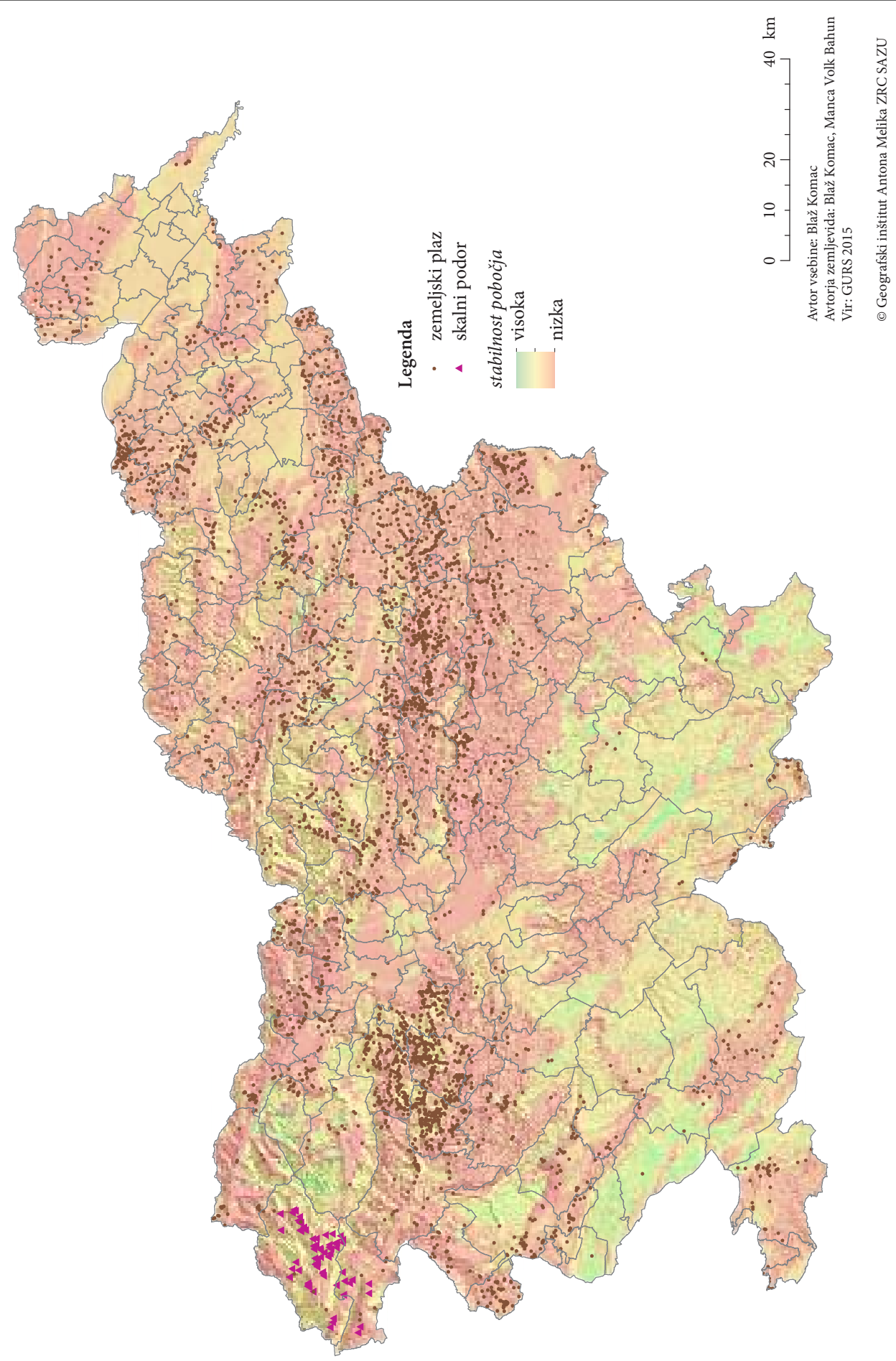

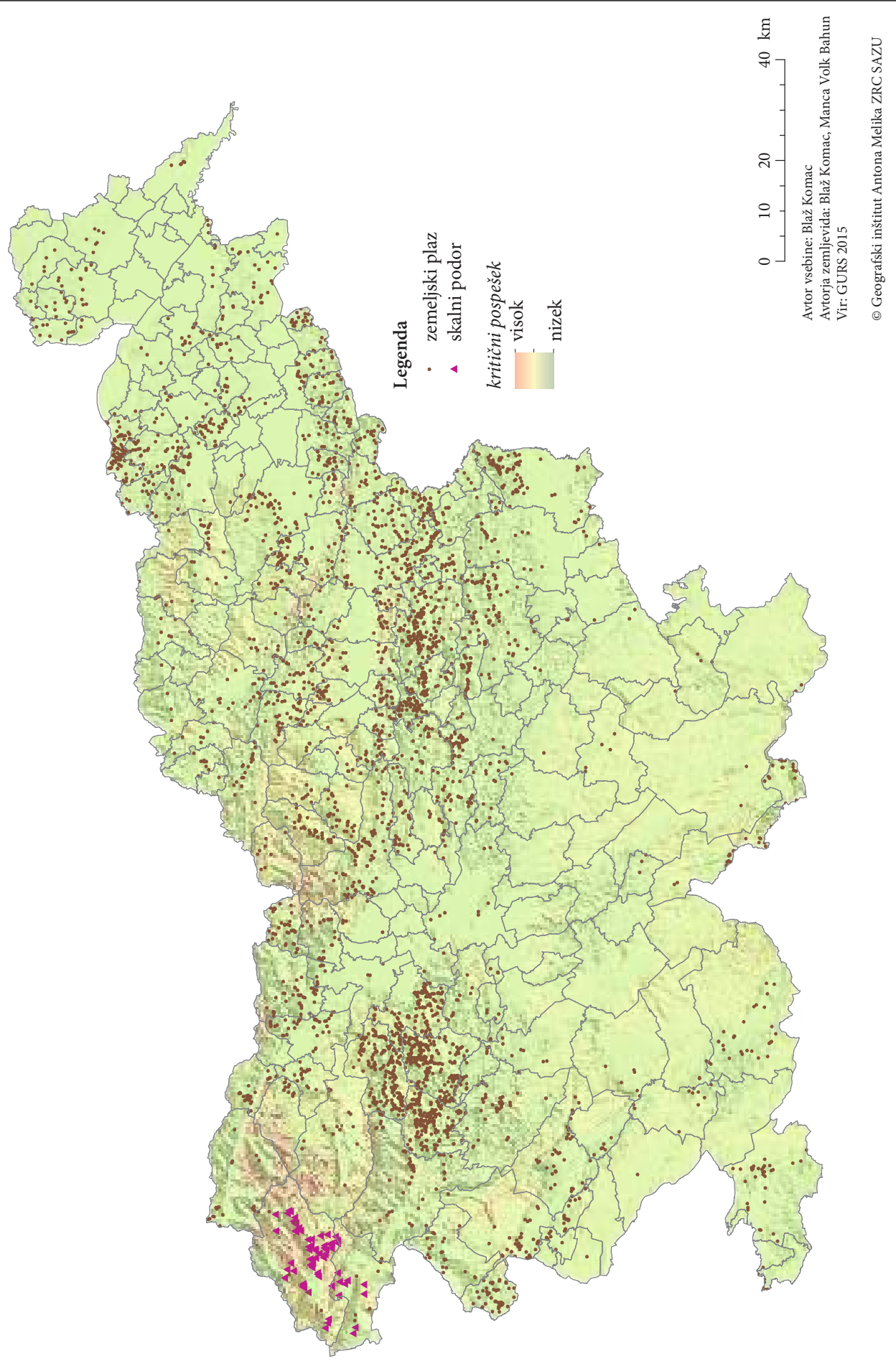


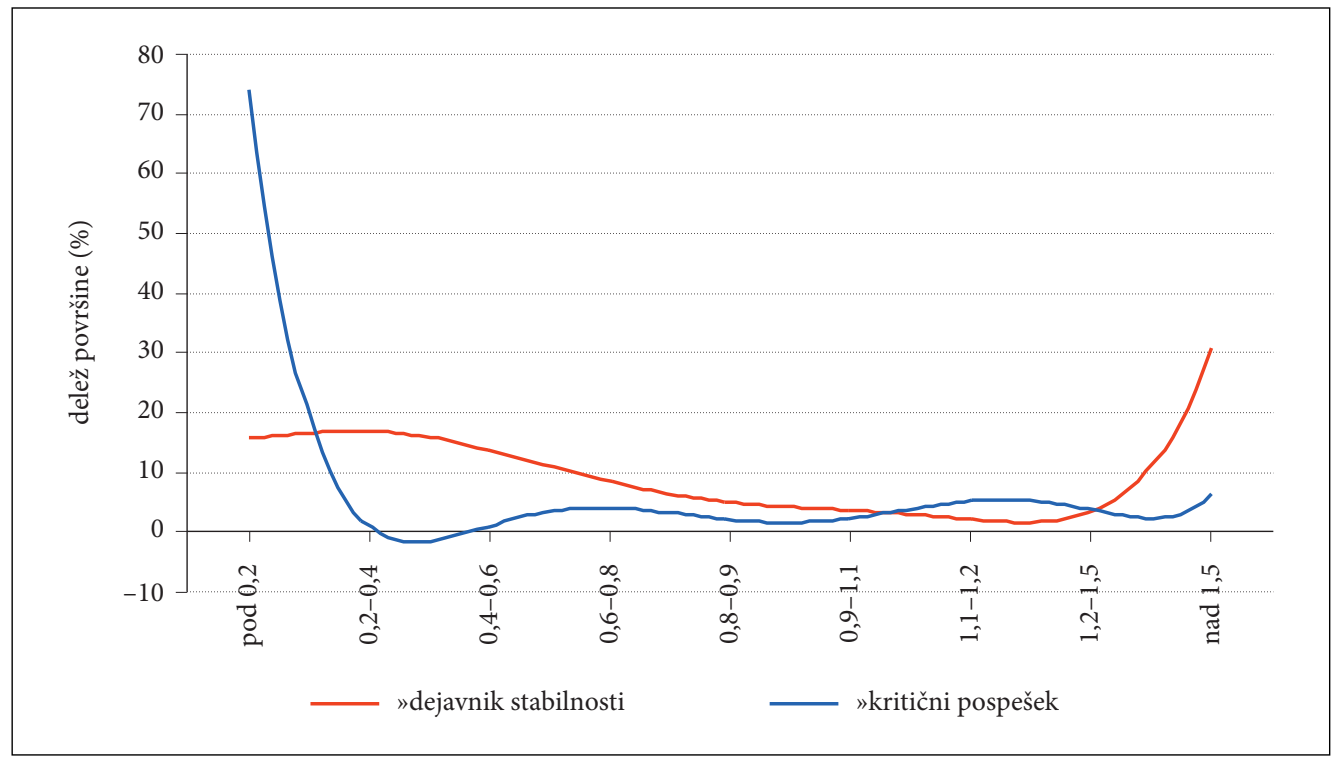

Slika 3: Dejavnik stabilnosti in kritični pospešek v Sloveniji.

(sliki 2 in 3). Tri četrtine zabeleženih pobočnih procesov je na območjih, ki jih model uvršča med nizke vrednosti kritičnega pospeška, slaba desetina je na območjih z zmerno vrednostjo (južna Slovenija), četrtina pa pri visokih (gorske in visokogorske pokrajine).

$\mathrm{Na}$ območjih $\mathrm{z}$ višjim kritičnim pospeškom $\mathrm{v}$ vzpetih pokrajinah na obpotresne pobočne procese (slika 4) vpliva predvsem vodoravni pospešek, zato so najpogostejši na ovršjih. To smo v Sloveniji že opazovali leta 1998 (Natek, Komac in Zorn 2003), izrazitejši pa je ta pojav ob močnejših potresih (Yong in Booth 2011).

Izračunani kritični pospešek bi bil ob potresu s povratno dobo 475 let (Lapajne, Šket Motnikar in Zupančič 2001) lahko presežen v gorskih pokrajinah iz plastovitega apnenca in dolomita ter na razgibanih območjih iz geomehansko mehkejših klastičnih sedimentnih kamnin in sedimentov: Posavsko hribovje, Julijske Alpe, Strojna, Kozjak in Pohorje ter Slovenske gorice, Cerkljansko, Škofjeloško, Polhograjsko in Rovtarsko hribovje in Kamniško-Savinjske Alpe. Vidrih in Ribičič (1994) sta zelo visoko verjetnost njihovega pojavljanja ugotovila za Kobariško, visoko verjetnost pa za Julijske in Kamniško-Savinjske Alpe.

Zgornje ocene potrjuje tudi zemljevid na sliki 4, ki prikazuje območja z večjo možnostjo nastanka obpotresnih pobočnih procesov. Zemljevid ne razlikuje zemeljskih plazov od skalnih podorov, temveč prikazuje območja, kjer potresni pospešek glede na odpornost kamnin in naklon pobočij (teoretično) lahko preseže kritični pospešek, pri katerem pride do premika. Z metodo je mogoče oceniti tudi velikost obpotresnega premika pobočja v centimetrih (angleško Newmark displacement), kar prikazuje slika 5. Velikost pričakovanega premika je odvisna od potresnega pospeška in lastnosti pobočja. Izračunana vrednost nam pove, kje lahko pride do premikov pobočja določene velikosti. Pričakovani premiki so

Slika 4: Območja, kjer pospešek ob potresu lahko preseže kritični pospešek.

Slika 5: Newmarkov premik in njegova verjetnost - prikazana so le območja, kjer sta pozitivni obe vrednosti. > str. 126

Slika 6: Možnost nastanka potresnih podorov po statistični metodi (Valagussa, Frattini in Crosta 2014). > str. 127 


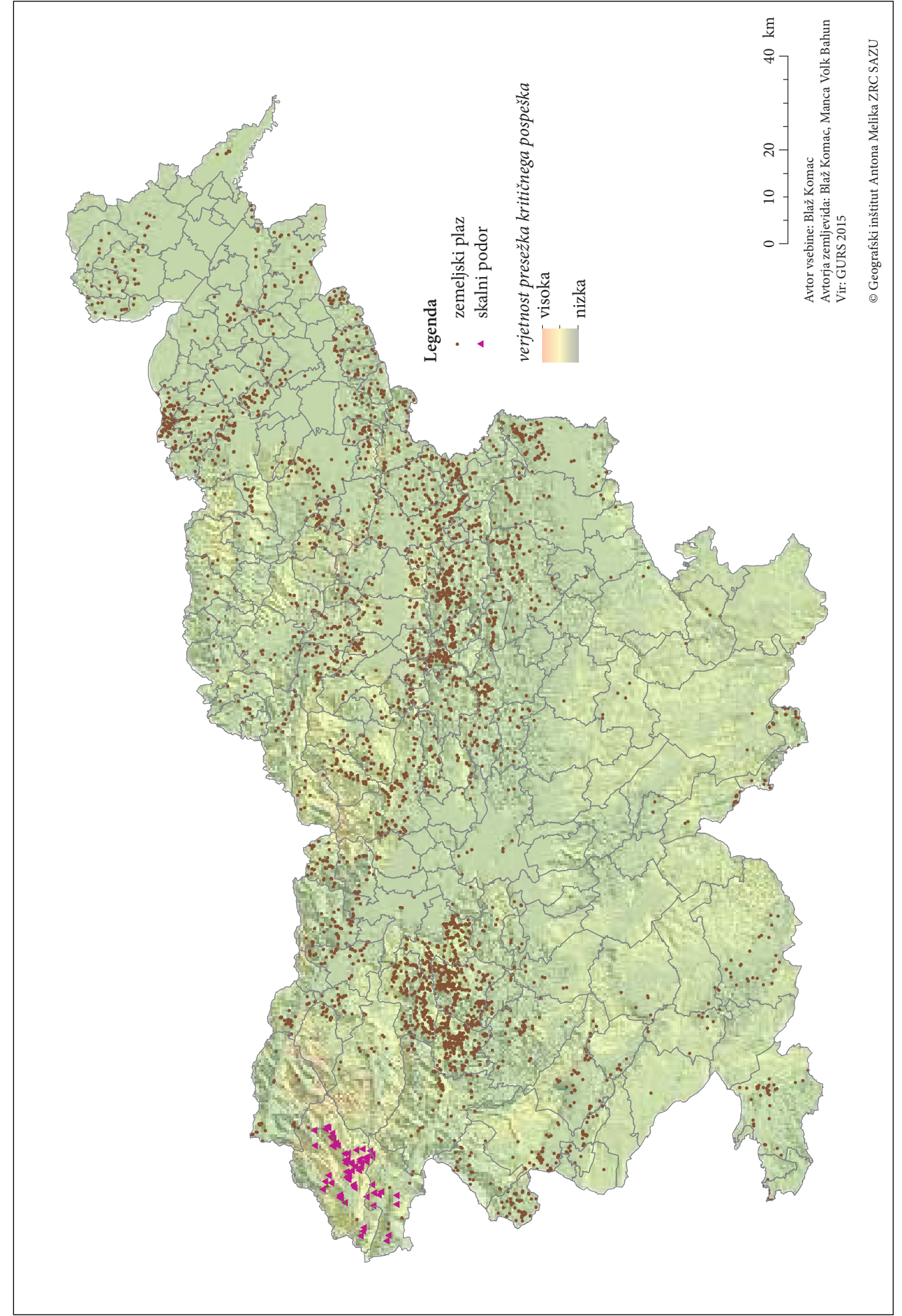



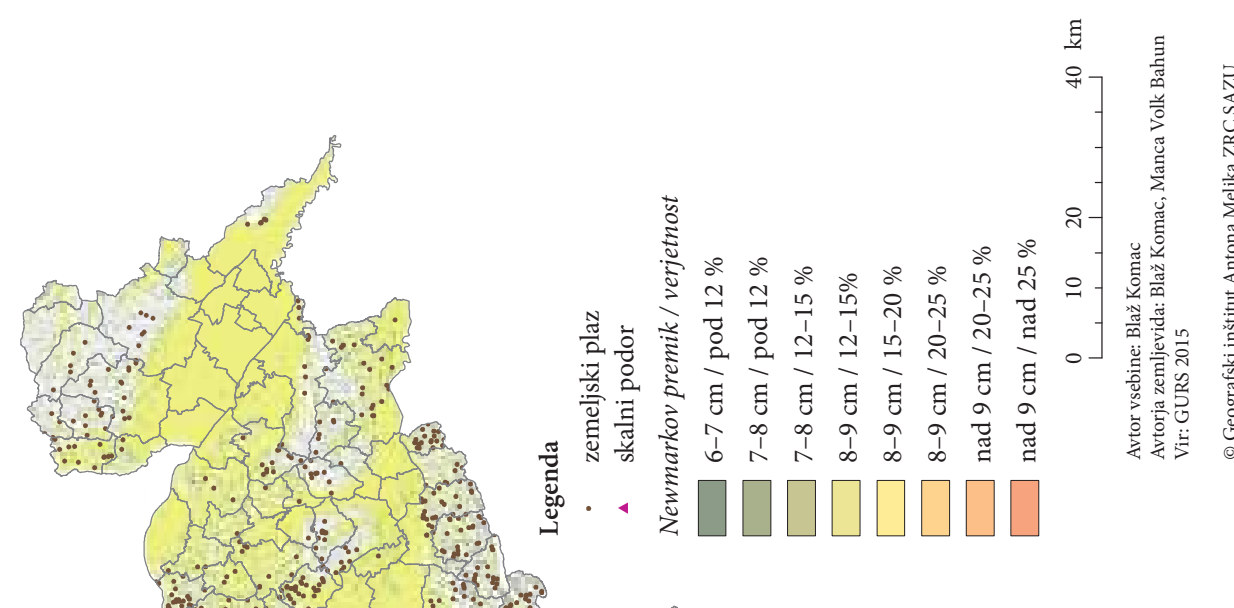

(3)

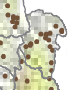
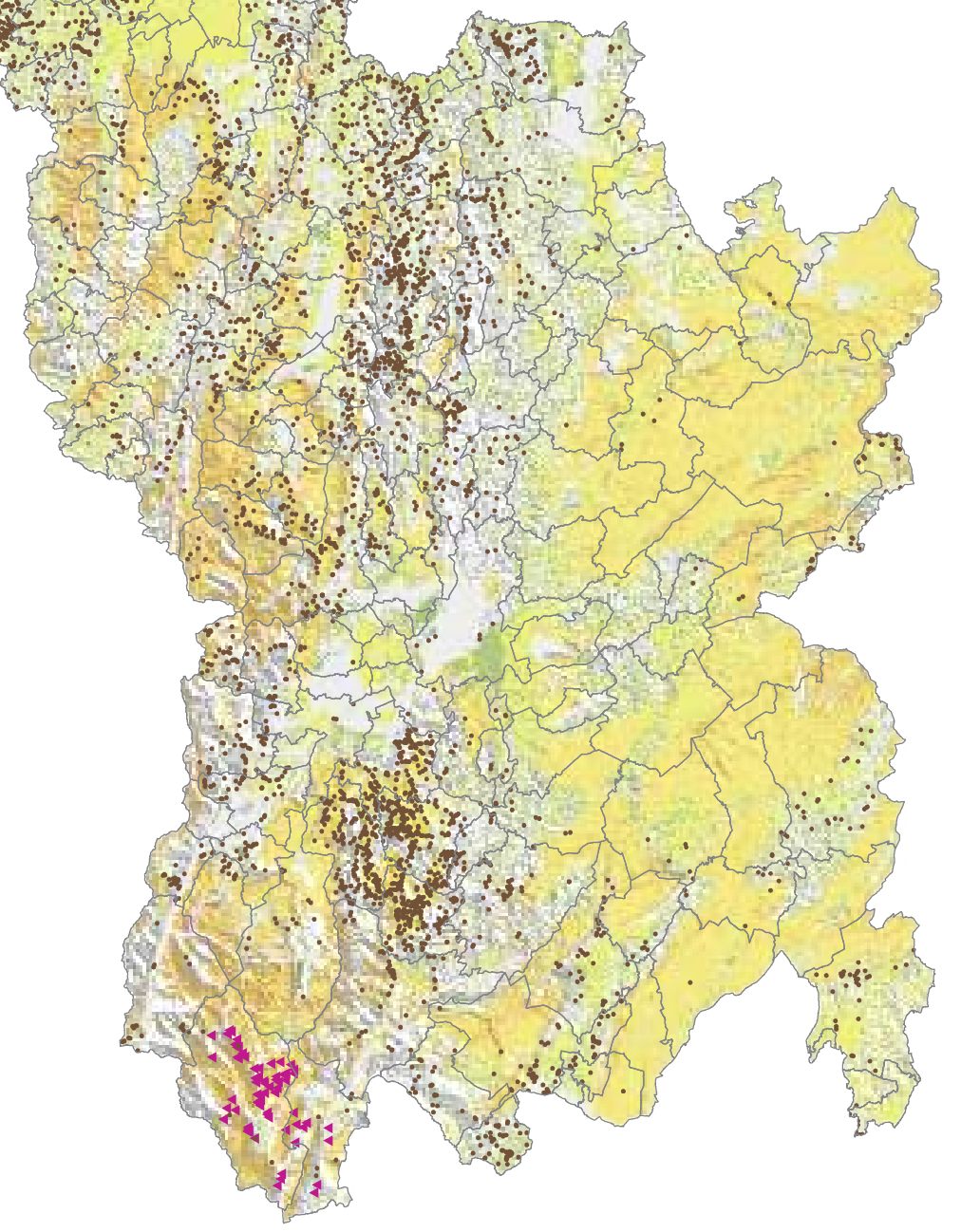

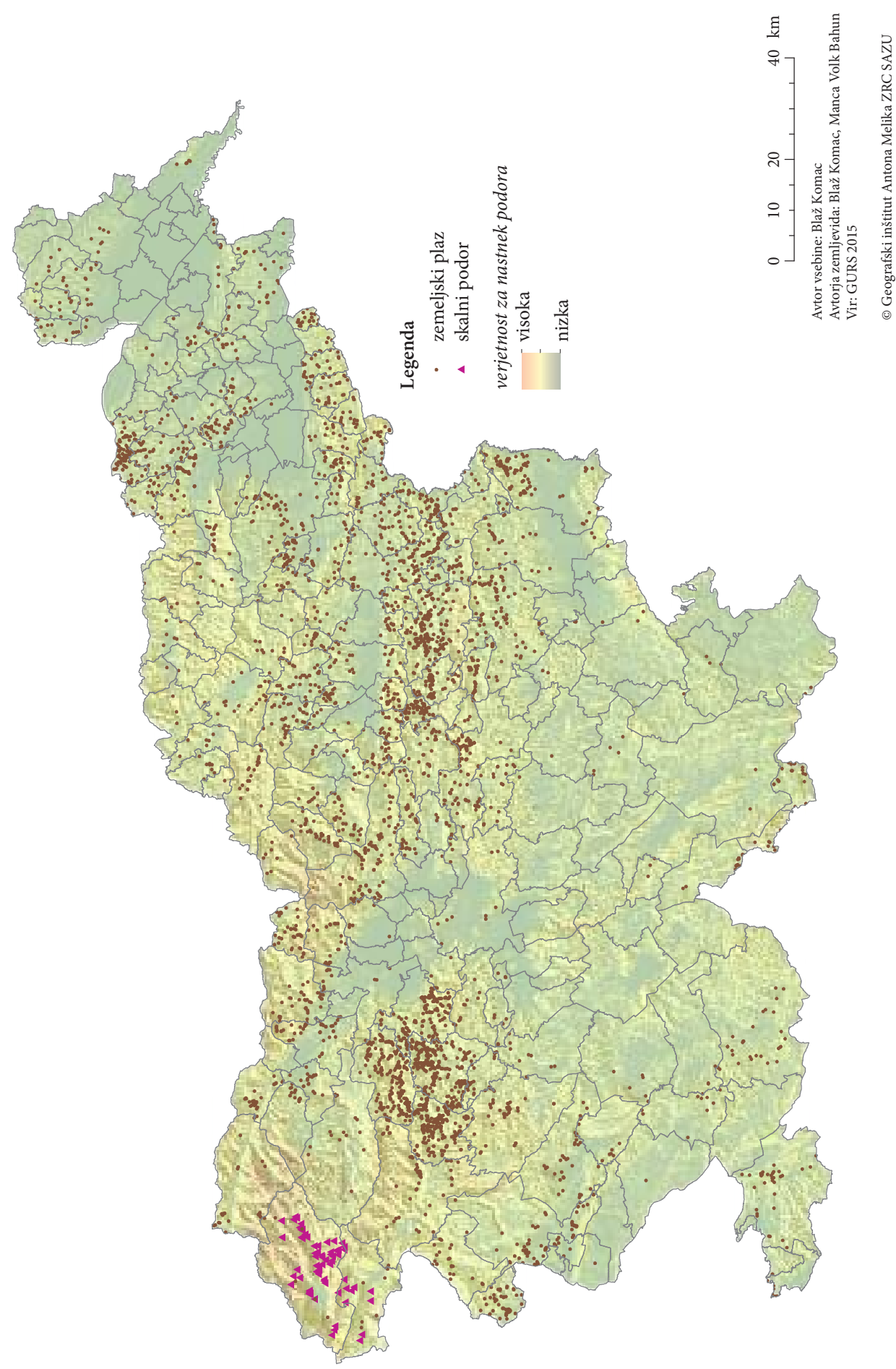
običajno podcenjeni, kljub temu pa dobimo okvirno oceno možnih velikosti deformacij pobočij ob potresnih plazovih (Jibson 1993).

Ker z zemljevida na sliki 4 brez poznavanja krajevnih razmer ni povsem jasno, katere pobočne procese opisuje, smo podatke $\mathrm{z}$ zemljevida primerjali $\mathrm{z}$ rezultati statistične analize možnosti proženja obpotresnih skalnih podorov. Valagussa, Frattini in Crosta (2014) so namreč na primeru 1006-ih obpotresnih podorov v Furlaniji 1976 ugotovili, da na njihovo proženje najbolj vplivajo naklon, potresna nevarnost in ukrivljenost površja. Podornost so izračunali z enačbo:

$$
\mathrm{D}_{(\text {verjetnost nestabilnosti pobočja })}=-4,73+0,067 \cdot \mathrm{S}+0,0041 \cdot \mathrm{PGA}+0,00011 \cdot \mathrm{C}
$$

kjer je $S$ naklon površja (stopinje), PGA pričakovani potresni pospešek tal ( $\left.\mathrm{cm} \mathrm{s}^{-2}\right), C_{\text {sk }}$ pa skupna ukrivljenost površja $(\mathrm{m} / \mathrm{m})$. Po tej metodi bi bila ob potresu nestabilna večina strmih vzpetih pokrajin, saj lastnosti kamnin niso upoštevane. Metoda slabše napove območja proženja zemeljskih plazov kot metoda potresnega pospeška, bolje pa skalne podore (slika 6).

Načeloma metoda ni neposredno prenosljiva na območja $\mathrm{z}$ drugačnimi kamninami in reliefom, kot so bili tisti, na podlagi katerih je bila narejena. Ker pa temelji na razmeroma velikem območju s pestro kamninsko sestavo (na preučevanem območju prevladujejo dolomit, apnenec, flišne kamnine, prisotni pa so še aluvialni in jezerski sedimenti ter konglomerat in breča, pa tudi peščenjak in laporovec), menimo, da je primerna za regionalno oceno možnosti nastanka obpotresnih skalnih podorov. Rezultati kažejo, da je za napovedovanje obpotresnih zemeljskih plazov primernejša metoda kritičnega pospeška, za napovedovanje skalnih podorov pa pravkar opisana metoda (slika 7).

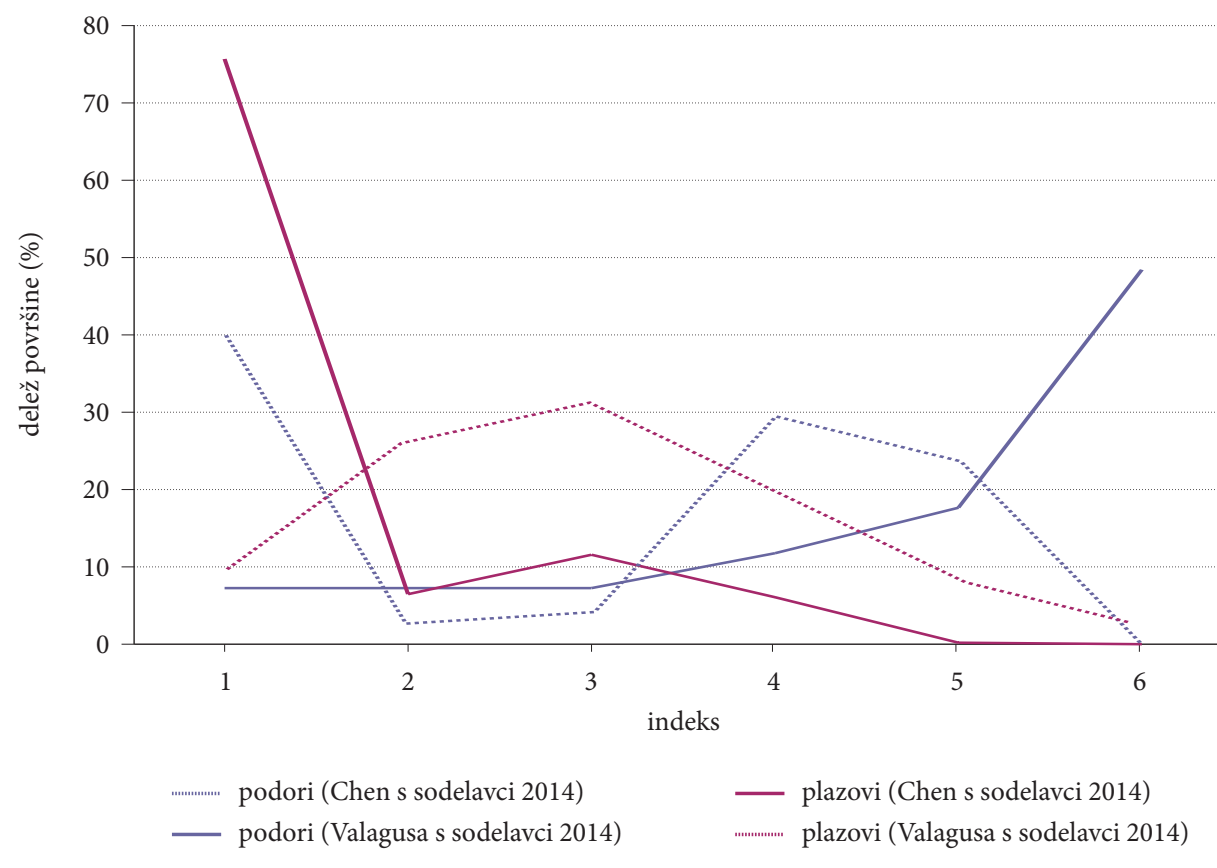

Slika 7: Primerjava učinkovitosti metod (Chen s sodelavci 2014; Valagussa, Frattini in Crosta 2014) za ugotavljanje plazovitosti (rdeče) in podornosti (modro). 


\section{Sklep}

Newmarkova metoda omogoča vpogled $\mathrm{v}$ lego in dinamiko obpotresnih pobočnih procesov. Čeprav tako kot vsi modeli posplošuje kompleksno pokrajinsko stvarnost (predpostavlja na primer vzporednost drsne ploskve s pobočjem, enakomerno strižno trdnost pobočja, enakomerno globino in nasičenost premikajoče se gmote), omogoča analizo z geografskimi informacijskimi sistemi. Tako dobimo vpogled v prostorsko razporeditev obpotresnih pobočnih procesov (predvsem zemeljske plazove) in regionalne razlike $\mathrm{v}$ pričakovanih premikih tal, pa tudi njihovo verjetnost. Model je primeren za analizo na državni in regionalni ravni, za natančnejši prikaz pa bi morali narediti laboratorijske analize lastnosti kamnin in sedimentov, posebej njihove geomehanske trdnosti, pa tudi razpokanost in zasičenosti z vodo, ki močno vpliva na plazenje (in s tem tudi na rezultate modela). Metoda je primerna za ugotavljanje območij, kjer ob potresih lahko pride do premikov gradiva na pobočjih oziroma nastanka zemeljskih plazov, ne moremo pa z njo oceniti možnosti obpotresnih premikov na določenem pobočju.

$\mathrm{Na}$ podlagi rezultatov $\mathrm{v}$ tem članku opisanega modeliranja sklepamo, da lahko približno tretjino pobočnih procesov v Nacionalni podatkovni bazi zemeljskih plazov prištejemo k skalnim podorom. Metoda razmeroma dobro napove plazovitost, saj se je skoraj $60 \%$ pobočnih procesov iz podatkovne baze sprožilo na območjih, ki so bila ovrednotena kot nestabilna, skoraj vsi pa na območjih z nizkim kritičnim pospeškom. S pomočjo Newmarkove metode smo ocenili tudi velikost in verjetnost premika tal ob potresih. Metoda daje $\mathrm{z}$ uporabo kritičnega pospeška vpogled $\mathrm{v}$ enega od pomembnih vzrokov nastanka pobočnih procesov (potresi).

$\mathrm{V}$ članku predstavljamo tudi oceno možnosti nastanka skalnih podorov ob potresih z enačbo, ki temelji na podatkih tisočih skalnih podorov po potresu v Furlaniji leta 1976. Ugotavljamo, da je približno polovica skalnih podorov po potresu v Posočju leta 1998 nastala na območjih z visoko ocenjeno možnostjo nastanka skalnih podorov in v bližini prelomov.

Dobra lastnost opisanih računskih pristopov je možnost ocene intenzitete potresa na neposeljenih, odročnih območjih in vrednotenje zemljevidov potresne, plazovne in podorne ter poplavne nevarnosti, kjer je oteženo neposredno merjenje premikov tal ob potresih, kar je pomemben napovedovalni dejavnik za proženje potresnih pobočnih procesov. Zemljevidi, ki jih izdelamo s predstavljeno metodo, so sicer primerni za uporabo na regionalni ravni oziroma so bolj informativnega značaja, saj ne upoštevajo vsakokratnih razmer in krajevnih lastnosti kamnin. Kljub temu pa jih lahko štejemo za enega od virov za boljše razumevanje součinovanja procesov v pokrajini (potres in pobočni procesi), s tem pa tudi kot prispevek za boljšo pripravljenost na med seboj povezane ali soodvisne (kaskadne) naravne nesreče.

Prikazani zemljevidi so torej tudi posredno merilo za ugotavljanje prožnosti pokrajine v smislu hitrosti obnove (povratna doba pobočnih procesov povečini ni znana, več pa imamo podatkov o povratni dobi sprožilnih dejavnikov, kot so padavine in potresi) in v smislu pripravljenosti na naravne nesreče. Članek tako pravzaprav obravnava kar štiri naravne nesreče, ki so med seboj lahko povezane: potres, zemeljski plaz, skalni podor in poplave.

\section{Viri in literatura}

Bavec, M., Tulaczyk, S. M., Mahan, S. A., Stock, G. M. 2004: Late Quarternary glaciation of the Upper Soča river region (Southern Julian Alps, NW Slovenia). Sedimentary Geology 165, 3-4. Amsterdam. DOI: http://dx.doi.org/10.1016/j.sedgeo.2003.11.011

Bishop, A. W. 1955: The use of the slip circle in the stability analysis of slope. Geotechnique 5-1. London.

Bouchon, M. 1973: Effect of topography on surface motion. Bulletin of the Seismological Society of America 63-2. Berkeley.

Buser, S. 1986: Osnovna geološka karta SFRJ 1:100.000, tolmač lista Tolmin in Videm (Udine). Zvezni geološki zavod. Beograd. 
Carson, M. A., Kirkby, M. J. 1972: Hillslope-form and process. Cambridge Geographical Studies 3. Cambridge.

Cecić, I. 2011: Idrijski potres 26. marca 1511 - kaj pravzaprav vemo o njem? Geografski obzornik 58-1. Ljubljana.

Chen, X.-L., Lui, C.-G., Lu, Y., Lin, C.-X. 2014: Critical acceleration as a criterion in seismic landslide susceptibility assessment. Geomorphology 217. Amsterdam. DOI: http://dx.doi.org/10.1016/ j.geomorph.2014.04.011

Costa, J. E., Schuster, R. L. 1988: The formation and failure of natural dams. Geological Society of America Bulletin 100-7. Boulder. DOI: http://dx.doi.org/10.1130/0016-7606(1988)100<1054:TFAFON>2.3.CO;2

Davis, L. L., West, L. R. 1973: Observed effects of topography on ground motion. Bulletin of the Seismological Society of America 63. Berkeley.

Digitalni model višin. Geodetska uprava Republike Slovenije. Ljubljana. Medmrežje: http://www.e-prostor.gov.si/ si/zbirke_prostorskih_podatkov/topografski_in_kartografski_podatki/digitalni_model_visin (15.1.2015).

Esposito, E., Porfido, S., Simonelli, A. L., Mastrolorenzo, G., Iaccarino, G. 2000: Landslides and other surface effects induced by the 1997 Umbria-Marche seismic sequence. Engineering Geology 58, 3-4. Amsterdam. DOI: http://dx.doi.org/10.1016/S0013-7952(00)00035-1

Fan, X., van Westen, C. J., Xua, Q., Gorum, T., Dai, C. 2012: Analysis of landslide dams induced by the 2008 Wenchuan earthquake. Journal of Asian Earth Sciences 57-5. Oxford. DOI: http://dx.doi.org/10.1016/ j.jseaes.2012.06.002

Gallen, S. F., Clark, M. K., Godt, J. W. 2014: Coseismic landslides reveal near-surface rock strength in a highrelief, tectonically active setting. Geology 43-1. Boulder. DOI: http://dx.doi.org/10.1130/ G36080.1

Gasparini, C., Anzidei, M., Conte, S., Del Mese, S., De Rubeis, V., Maramai, A., Massucci, A,. Riguzzi, F., Tertulliani, A., Tosi, P., Vannucci, C., Vecchi, M. 1997: Indagine macroseismica per la sequenza sismica Umbro-Marchigiana settembre-ottobre 1997. ING 593. Bologna.

Geli, L., Bard, P. Y., Julien, B. 1988: The effect of topography on earthquake ground motion: a review and new results. Bulletin of the Seismological Society of America 78-1. Berkeley.

Grošelj, K. 2004: Potres v Posočju 1998. Ujma 17-18. Ljubljana.

Guo, W. D. 2013: Theory and Practice of Pile Foundations. Boca Raton.

Harp, E. L., Jibson, R. W. 1996: Landslides triggered by the 1994 Northridge, California earthquake. Bulletin of the Seismological Society of America 86-1b. Berkeley.

Hoek E., Brown, E. T. 1980: Underground Excavations in Rock. London.

Hoek, E., Brown, E. T. 1988: The Hoek-Brown failure criterion - a 1988 update. Proceedings of the 15th Canadian Rock Mechanics Symposium. Toronto.

Jibson, R. W. 1993: Predicting earthquake-induced landslide displacement using Newmark's sliding block analysis. Transportation Research Record 1411. Washington.

Jibson, R. W. 2007: Regression models for estimating coseismic landslide displacemenz. Engineering Geology 91, 2-4. DOI: http://dx.doi.org/10.1016/j.enggeo.2007.01.013

Jibson, R. W., Harp, E. L., Michael, J. M. 2000: A method for producing digital probabilistic seismic landslide hazard maps. Engineering Geology 58, 3-4. Amsterdam. DOI: http://dx.doi.org/10.1016/ S0013-7952(00)00039-9

Jibson, R. W., Michael, J.A. 2009: Maps showing seismic landslide hazard in Anchorage, Alaska. Medmrežje: http://pubs.usgs.gov/sim/3077/ (9.11.2015).

Katalog potresov. Agencija Republike Slovenije za okolje. Ljubljana, 2010. Medmrežje: http://gis.arso.gov.si/ geoportal/catalog/search/resource/details.page?uuid=\%7B8803C868-0C29-4B7E-B6C1 47457286F392\%7D (30.1.2015).

Keefer, D. K. 1984: Landslides caused by earthquakes. Geological Society of America Bulletin 95-4. Boulder. DOI: http://dx.doi.org/10.1130/0016-7606(1984)95<406:LCBE>2.0.CO;2 
Keefer, D. K., Wasowski, J., Del Gaudio, V. 2006: Special issue from the European Geosciences Union Symposium on landslides induced by earthquake and volcanic activity. Engineering Geology 86, 2-3. Amsterdam. DOI: http://dx.doi.org/10.1016/j.enggeo.2006.02.009

Koloski, J. W., Schwarz, S. D., Tubbs, D. W. 1989: Geotechnical properties of geologic materials. Engineering Geology in Washington 1. Washington Division of Geology and Earth Resources Bulletin 78. Medmrežje: http://www.tubbs.com/geotech/geotech.htm (15.1.2015).

Komac, B., Natek, K., Zorn, M. 2008: Geografski vidiki poplav v Sloveniji. Geografija Slovenije 20. Ljubljana. Komac, B., Zorn, M. 2002: Recentni pobočni procesi v Zgornjem Posočju. Geografski obzornik 49-1. Ljubljana.

Komac, B., Zorn, M. 2007: Pobočni procesi in človek. Geografija Slovenije 15. Ljubljana.

Komac, B., Zorn, M. 2009: Pokrajinski učinki skalnega podora v Pologu. Geografski vestnik 81-1. Ljubljana.

Komac, M. 2005: Intenzivne padavine kot sprožilni dejavnik pri pojavljanju plazov v Sloveniji. Geologija 48-2. Ljubljana. DOI: http://dx.doi.org/10.5474/geologija.2005.022

Komac, M., Fajfar, D., Ravnik, D., Ribičič, M. 2008: Nacionalna podatkovna baza zemeljskih plazov. Geografski informacijski sistemi v Sloveniji 2007-2008. Ljubljana.

Korup, O. 2002: Recent research on landslide dams - a literature review with special attention to New Zealand. Progress in Physical Geography 26-2. London. DOI: http://dx.doi.org/10.1191/0309133302pp333ra

Korup, O., McSaveney, M.J., Davies, T.R.H. 2004: Sediment generation and delivery from large historic landslides in the Southern Alps, New Zealand. Geomorphology 61, 1-2. Amsterdam. DOI: http://dx.doi.org/10.1016/j.geomorph.2004.01.001

Košir, M., Cecić, I. 2011: Potres 26. marca 1511 v luči novih raziskav. Idrijski razgledi 56-1. Idrija.

Lapajne, J., Šket Motnikar, B., Zupančič, P. 2001: Projektni pospešek tal [g] s povratno dobo 475 let. Uprava Republike Slovenije za geofiziko. Ljubljana.

Meunier, P., Hovius, N., Haines, J. A. 2008: Topographic site effects and the location of earthquake induced landslides. Earth and Planetary Science Letters 275, 3-4. Amsterdam. DOI: http://dx.doi.org/10.1016/ j.epsl.2008.07.020

Mikoš., M., Fazarinc, R., Ribičič, M. 2006: Sediment production and delivery from recent large landslides and earthquake-induced rock falls in the Upper Soča River Valley, Slovenia. Engineering Geology 86, 2-3. Amsterdam. DOI: http://dx.doi.org/10.1016/j.enggeo.2006.02.015

Miles, S. B., Ho, C. L. 1999: Rigorous landslide hazard zonation using Newmark's method and stohastic ground motion simulation. Soil Dynamics and Earthquake Engineering 18-4. Southampton. DOI: http://dx.doi.org/10.1016/S0267-7261(98)00048-7

Miles, S. B., Keefer, D. K. 2001a: Seismic landslide hazard for the city of Berkeley, California. US Geological Survey Miscellaneous Field Studies Map MF-2378. Medmrežje; http://pubs.usgs.gov/mf/ 2001/2378/ (9.11.2015).

Miles, S. B., Keefer, D. K. 2001b: Seismic landslide hazard for the cities of Oakland and Piedmont, California: US Geological Survey Miscellaneous Field Studies Map MF-2379. Medmrežje: http://pubs.usgs.gov/mf/2001/2379/ (9.11.2015).

Murphy, W., Petley, D. N., Risdon, G., Chien, M.C. 2000: Topographic effects influencing large scale slope failure during the 21st September Chichi earthquke, Taiwan. Proceedings of the Second Euro-Conference on Global Change and Catastrophe Risk Management - Earthquake Risks in Europe. Medmrežje: http://www.iiasa.ac.at/Research/RMS/july2000/Papers/murphy0709.pdf (6.11.2015).

Natek, K., Komac, B., Zorn, M. 2003: Mass movements in the Julian Alps (Slovenia) in the aftermath of the Easter earthquake on April 12, 1998. Studia geomorphologica Carpatho-Balcanica 37. Warszawa.

Newmark, N. M. 1965: Effects of earthquakes on dams and embankments. Geotechnique 15-2. London.

Parameters of rocks. Fine - civil software engineering. Medmrežje: http://www.finesoftware.eu/help/geo5/ en/parameters-of-rocks-01/ (15.1.2015).

Petley, D. N., Murphy, W. 2001: Topographic amplification and the initiation of landslides in Taiwan. Proceedings of the fifth International Conference on Geomorphology. Tokyo. 
Poljak, M. 2007: Strukturno-tektonska karta Slovenije 1:250.000, izdelana po podatkih Osnovne geološke karte SFRJ 1:100.000. Ljubljana.

Prestininzi, A., Romeo, R. 2000: Earthquake-induced ground failures in Italy. Engineering Geology 58, 3-4. Amsterdam. DOI: http://dx.doi.org/10.1016/S0013-7952(00)00044-2

Schellart, W. P. 2000: Shear test results for cohesion and friction coefficients for different granular materials: scaling implications for their usage in analogue modelling. Tectonophysics 324, 1-2. Amsterdam. DOI: http://dx.doi.org/10.1016/S0040-1951(00)00111-6

Shear Strength and Discontinuities. Medmrežje: https://www.rocscience.com/hoek/corner/4_Shear_ strength_of_discontinuities.pdf (15.1.2015).

Sjöberg, J. 1997: Estimating Rock Mass Strength Using the Hoek-Brown Failure Criteria and Rock Mass Classification. Luleå.

Soil and Rock Classification, Simple Tests, and Correlations. Medmrežje: http://www.boretekinc.com/ documents/app-c.pdf (22.1.2015).

Spudich, P., Hellweg, M., Lee, W. H. K. 1996: Directional topographic site response at Tarzana observed in aftershocks of the 1994 Northridge, California, earthquake: implications for mainshock motions. Bulletin of the Seismological Society of America 86-1. Berkeley.

Valagussa, A., Frattini, P., Crosta, G. B. 2014: Quantitative probabilistic hazard analysis of earthquake-induced rockfalls. Landslide Science for a Safer Geoenvironment 3. Heidelberg. DOI: http://dx.doi.org/ 10.1007/978-3-319-04996-0_33

Vidrih, R., Ribičič, M. 1994: Vpliv potresov na nastanek plazov v Sloveniji. Prvo slovensko posvetovanje o zemeljskih plazovih. Idrija.

Vidrih, R., Ribičič, M. 1998: Porušitve naravnega ravnotežja v hribinah ob potresu 12. aprila 1998. Geologija 41. Ljubljana. DOI: http://dx.doi.org/10.5474/geologija.1998.019

Vidrih, R., Ribičič, M., Suhadolc, P. 2001: Seizmological effects on rocks during the 12. April 1998 upper Soča Territory earthquake (NW Slovenia). Tectonophysics 330, 3-4. Amsterdam. DOI: http://dx.doi.org/ 10.1016/S0040-1951(00)00219-5

Wilson, R. C., Keefer, D. K. 1985: Predicting areal limits of earthquake-induced landsliding. Evaluating Earthquake Hazards in the Los Angeles Region - An earth-science perspective. U.S. Geological Survey Professional Papers 1360.

Yin, Y., Wang, F., Sun, P. 2009: Landslide hazards triggered by the 2008 Wenchuan earthquake, Sichuan, China. Landslides 6-2. Berlin. DOI: http://dx.doi.org/10.1007/s10346-009-0148-5

Yong, C., Booth, D. C. 2011: The Wenchuan Earthquake of 2008: Anatomy of a Disaster Anatomy of a Disaster. Berlin. DOI: http://dx.doi.org/10.1007/978-3-642-21159-1

Zemljevid tipov kamnin. Geografski inštitut Antona Melika ZRC SAZU, različica 9. 12.2012. Ljubljana, 2012.

Zorn, M. 2002a: Rockfalls in Slovene Alps. Geografski zbornik 42. Ljubljana.

Zorn, M. 2002b: Podori na Dobraču. Geografski vestnik 74-2. Ljubljana.

Zorn, M., Komac, B. 2008: Zemeljski plazovi v Sloveniji. Georitem 8. Ljubljana.

\section{Summary: Co-seismic slope processes in Slovenia}

(translated by Nataša Pregl)

Concurrent slope processes often cause the most damage during earthquakes. Whereas events like these only received global attention during the earthquake in the Chinese region of Wenchuan in 2008, Slovenia experienced them on April 12th 1998 when approximately a hundred rockfalls were triggered during the strongest earthquake on Slovenian territory in the 20th century.

Apart from slope stability, one of the main causal factors of seismic slope processes is the expected peak ground acceleration. The article describes an assessment of the critical ground or slope acceleration 
and stability on Slovenian territory, and therefore an estimate of the risk of slope process activation and expected ground movements during earthquakes. A calculation of the abovementioned elements by means of the so-called Newmark's method includes slope inclination, cohesion and specific rock weight, the depth and inclination of the slide surface as well as gravitational acceleration. The estimated peak ground acceleration for Slovenia with a return period of 475 years was also taken into consideration. The result was evaluated based on the data on slope processes obtained from the Slovenian National Landslide Database, and on the rockfalls that were triggered during the earthquake in Soča Valley in 1998.

Based on relief and rock data, the critical acceleration that may trigger slope processes was calculated for the territory of Slovenia. The critical acceleration value was then compared with the expected earthquake acceleration to establish the areas with a higher risk of seismic slope processes. Both the safety factor and the Newmark's movement were calculated for these areas as well.

The spatial distribution of the safety factor that shows the stability of slopes very well matches the data on the position of slope processes from the Slovenian National Landslide Database, i.e. $60 \%$ of landslides are in unstable areas, $4 \%$ in relatively stable areas and $36 \%$ in stable areas.

Landslides usually occur more frequently at lower values of critical ground acceleration, and less frequently at higher values since a higher critical acceleration value means that a stronger force is needed to activate the movement of the slope or the material accumulated on the slope. Three quarters of the recorded slope processes have been triggered at low critical acceleration values, less than a tenth was triggered at moderate values and a quarter was triggered at high values.

A comparison of the calculated critical acceleration and the acceleration demonstrated during earthquakes of expected magnitude (Lapajne, Šket Motnikar and Zupančič 2001) shows that during an earthquake with a return period of 475 years, the critical acceleration of slopes was obtained mainly in the Alpine Sava Hills, the Julian Alps, on Strojna, Kozjak and Pohorje, in Slovenske gorice, in the Cerkno, Škofja Loka, Polhov Gradec and Rovte hills, and in the Kamnik-Savinja Alps. In addition, the position of unstable slopes for such processes in Slovenia was calculated based on the statistical analysis of 1006 co-seismic rockfalls in the Friuli region in 1976. Further on, co-seismic slope processes were analysed from the perspective of their position on the slope and based on faults. During earthquakes, slope processes most frequently start on the upper parts of the slopes - where the seismic acceleration is higher due to the topographical effect and because of stronger oscillation in comparison with the lower parts - and near the faults. During the Soča Valley earthquake in 1998, most of the slope processes were triggered a few hundred metres above the bottom of the valley (Natek, Komac and Zorn 2003). Approximately half of them were rockfalls.

Co-seismic slope processes are an important factor in the reshaping of mountain ridges since they "remove " and round off the highest, convex parts of the slopes and reduce the inclination of the steepest parts of the slopes respectively, and at the same time ensure an exceptional inflow of sediments into the rivers which often causes their impoundment.

This article estimates the risk of landslide and rockfall activation during in the event of an earthquake. The methods described are applicable for assessment on a regional level. The Newmark's method that takes into consideration the properties of rocks and the surface relief can be used for evaluating the statistical methods of landslide risk assessment (Zorn in Komac 2008). According to our estimates, roughly a third of the slope processes recorded in the Slovenian National Landslide Database can be classified as rockfalls. 
